\title{
FELIPE II Y FELIPE III COMO PATRONOS MUSICALES ${ }^{1}$
}

\author{
Luis ROBLEDO
}

\begin{abstract}
A reflection is made about the concept of musical patronage and about its extent in the Spanish court envioronment of the Habsburg monarchy taking into account the different institutional establishments and the sonorous environments conformed by them. Through the interrelation between such establishments and the monarch image different models of patronage appear: a) the one of Philip II, without a strong parsonal interest, but with a close attirude towards the institutional organization; b) the one of Philip III, personally implied in musical activity, which prompts the institution being conformed and reshaped by the monarch musical tastes.
\end{abstract}

\section{Resumen}

Se hace una reflexión sobre el concepto de patronazgo musical y sobre el alcance del mismo en el entorno cortesano español de la monarquía Habsburgo tomando en consideraciòn los diferentes estamentos institucionales y los ambientes sonoros que ellos conforman. A través de la interrelación entre dicho entorno y la figura del monarca, dos diferentes modelos de patronazgo aparecen: a) el de Felipe II, sin un interés personal marcado, pero muy atento al marco institucional, y cuya actitud sienta las bases de organización musical de la corte española; b) el de Felipe III, implicado personalmente en la actividad musical, lo que hace que la institución se acomode a los gustos del monarca y sea redefinida en función de ellos.

Antonio Palomino narra en sus Vidas una anécdota reveladora de la actitud personal de Felipe II con su pintor de cámara Alonso Sánchez Coello:

«... de donde teniendo el rey la llave, por un tránsito secreto... solía muchas veces entrar en su casa a deshora... Otras veces le cogía sentado pintando, y llegando quedito por las espaldas, le ponía las manos sobre sus hombros, y queriendo Alonso levantarse a hacer el debido comedimiento, le hacía sentar y proseguir en su pintura de que el rey gustaba mucho.» $^{2}$

¿Es imaginable una escena semejante si, en vez de un pintor, se tratase de, digamos, un maestro de capilla dando término a un salmo o a un villancico? Difícilmente: el proceso, el resul-

1. El presente artículo es una versión ampliada de la comunicación presentada en la Study Session: Music, Politics and Patronage in Spanish and Portuguese Dominions in the Early Modern Period, dentro del 16th International Congress de la International Musicological Society, Londres, 14-20 de agosto de 1997.

2. Palomino 1986, 60-61. 
tado final, el destino y las condiciones para la percepción de ambas actividades son muy diferentes. Sin llegar a extremar un parangón al modo dieciochesco, nos vemos irremediablemente abocados a establecer una comparación entre actividades artísticas diferentes precisamente por la diferente relación de dependencia con el poder. ¿Existe una especificidad del hecho musical en su relación con el poder?, o dicho de otra manera, ¿presta la música parecidos o diferentes servicios, con respecto a otras manifestaciones artístico-culturales, al monarca como persona y al aparato de poder que éste encarna? Fijémonos por ejemplo en el retrato que, como ha puesto de manifiesto admirablemente Javier Portús refiriéndose a los Habsburgo españoles, no sólo brindaba la imagen del monarca, sino que imponía su virtual presencia, propiciando la copia mecanismos de comportamiento semejantes a los implicados por el natural. ${ }^{3}$ ¿Existe el retrato musical? Sabemos que sí, en cierto modo: el que se obtiene mediante el procedimiento del «soggetto cavato» y que puede ensalzar el «modelo» hasta colocarlo parejo a la divinidad, tal como sucede en la misa Philippus Secundus Rex Hispaniae del último maestro de capilla de Felipe II, Philippe Rogier, verbigracia en el final del Sanctus, cuando a la última aparición del cantus firmus «Phi-lip-pus Se-cun-dus Rex His-pa-ni-ae...» responden las voces restantes «... in excelsis». En última instancia, y en un sentido amplio, lo que el monarca espera tanto del pintor como del músico tiene la misma orientación: la afirmación de su imagen, una afirmación que sea convincente desde el punto de vista de la percepción de los demás y, a la vez, que procure satisfacción personal al interesado. En definitiva, lo que el monarca espera de ambos es obvịo en términos de relación amo-criado: que se le sirva fielmente y a su agrado. Sólo que la manera en que uno y otro lo llevan a cabo reviste muy diferentes caracteres. Cobra aquí todo su sentido la importancia del carácter mediador que Claudio Annibaldi ha atribuido a «il mondo», ese territorio común al patrón y al hacedor de ficciones (el artista) en el que escenario y público se confunden e interactúan, territorio que condiciona el arbitrio de soluciones diversas para la simbolización de la epifanía del poder. ${ }^{4}$

Pero, si no vemos al monarca asomarse al proceso creativo del músico compositor, sí cabe, en cambio, imaginarlo escuchando atentamente a cantores o instrumentistas. La dimensión temporal, suplementaria en la atención al objeto pictórico que todavía no se da como tal, es, huelga decirlo, esencial en la actividad musical que es, ante todo, acontecimiento. Podemos verlo, incluso, participando él mismo de dicho acontecimiento, en cuyo caso tal actividad continúa ofreciéndose en dos esferas simultáneas, la del deleite personal y la del refuerzo de la propia imagen, según veremos, adquiriendo mayor relieve una u otra dependiendo de las modalidades de participación - no significa lo mismo cantar, tañer o danzar - y de las circunstancias.

La reflexión anterior nos ha de permitir establecer ciertas constantes en las que se van a enmarcar modelos de patronazgo musical tan diferentes entre sí como los que van a encarnar Felipe II y Felipe III de España. Pero no son las únicas. Quisiera proponer otros enfoques convergentes que ayudaran a esclarecer los diferentes factores que conforman la relación entre la

3. PORTÚs PÉREZ 1994.

4. ANNIBALDI 1993 y 1997. 
actividad musical y la estructura cortesana que le da cabida. Esta última apreciación es ya, en sí misma, equívoca, porque en la corte no existe una sola actividad musical: son múltiples y diferenciados los paisajes sonoros que dan cobertura a la actividad cortesana, como son múltiples las imágenes del propio monarca y de su entorno. Hay un monarca prepotente y batallador al que acompaña su correspondiente «puesta en escena», otro piadoso, otro íntimo, otro festivo y relajado; y a cada una de esas imágenes se ciñe un paisaje musical determinado. Habría, pues, que intentar delimitar el concepto mismo de música en la corte.

Otro aspecto que me gustaría cuestionar es, a la vez, terminológico y de concepto, aspecto éste inseparable de la lengua que se esté utilizando. Me refiero al término castellano mecenazgo que suele emplearse de manera intercambiable con el de patronazgo -o patrocinio, quizá más adecuado-. Creo que no es necesario caer en un nominalismo estéril, ni pasearse de manera bizantina por los estrechos límites del diccionario, para plantearse la conveniencia de utilizar uno u otro término, o al menos hacer una reflexión previa, porque creo que se ha abusado del término mecenas para referirse al patrón que promociona o sustenta una actividad y una institución musicales. La imprecisión entre los límites de ambos conceptos y términos se hace más evidente si los comparamos con los más frecuentemente utilizados en otras lenguas: patronage en inglés, mecenatismo y committenza en italiano, patronage en francés, etc. Creo que, en el caso español, una comparación rigurosa entre la iniciativa de la institución monárquica de los Habsburgo para promocionar expresiones artísticas en general y para hacer lo mismo con obras o acontecimientos musicales mostraría una diferencia muy marcada con desventaja para la música, al margen de casos aislados o etapas históricas muy concretas que, ciertamente, los hay.

La servidumbre, no sólo de las diferentes artes, sino de cada una de las diferentes manifestaciones musicales, determina la relación de dependencia entre música y poder. También determina la actitud del monarca, que puede ir desde la atención e interés personales hasta el distanciamiento. Dentro de esta gama de actitudes podríamos aventurarnos a señalar dónde acaba el patrón y dónde comienza el mecenas. Para que haya verdadero mecenazgo entiendo que se hace necesaria - aunque no es suficiente - una actitud de deleite, de disfrute personal hacia el objeto o hacia el acontecer artístico, algo parecido, salvando todas las distancias, a lo que entendemos como actitud estética. Es decir, el mecenazgo comportaría una actitud de interés personal hacia individuos, actividades, objetos, y, paradójicamente, una actitud de alguna manera «desinteresada» en cuanto a los favores que se conceden.

Pero el monarca se debe a sus súbditos, a su corte, a su familia; en suma, a la institución monárquica. Difícilmente puede separar su propio interés del interés general. En este sentido es, objetivamente, el patrón por antonomasia, teniendo que vertebrar un conjunto de fuerzas heterogéneas que en diferentes direcciones configuran las variadas caras del poder. Esta interdependencia constante entre lo personal y lo institucional nos lleva a considerar otro enfoque posible del tema. Así, debemos distinguir entre: a) lo que desea, o prefiere, el patrón; b) lo que conviene a la institución; y c) el intermediario que articula y concilia ambas cosas, en figura de valido, ministro, secretario, jefe de un departamento de la casa real, o cualquiera que sea. Desde el punto 
de vista institucional, es obvio que la actividad musical ha de estar sometida a un criterio básico de funcionalidad: se produce y es diseñada para garantizar una correcta andadura de aquélla.

Resulta ocioso señalar que todos los factores mencionados no actúan por separado, sino que se interrelacionan. Es el cruce de todos ellos lo que nos podrá dar una imagen global del patronazgo o mecenazgo musical de los dos Habsburgo españoles que nos ocupan.

Los diferentes paisajes sonoros a que he aludido anteriormente venían determinados por la misma organización de la casa real española a través de los departamentos que la componían, una organización producto de la yuxtaposición de dos modelos de casa real, la llamada Casa de Borgoña, heredera de la casa de los antiguos duques de Borgoña, que había sido introducida en España por Felipe I el Hermoso, y la llamada Casa de Castilla que seguía el modelo tradicional castellano. Esta peculiar y compleja organización cortesana, de la que fue artífice Felipe II, se mantendrá hasta el siglo XVIII. ${ }^{5}$ De los departamentos que conforman la casa real española en esta época, principalmente son tres los que «suenan»: la capilla — toda una institución en sí misma orientada a la exaltación de la devoción y del poder, en suma, a la sacralización del monarca-, la caballeriza - portadora fundamentalmente de la enseña sonora de tal poder: la música heráldica de trompetas y atabales, pero también conformadora de la imagen externa del monarca- y la cámara - donde la función de la música se reparte entre el esparcimiento y la legitimación de la figura del monarca- . Ni que decir tiene que la intervención en cada departamento de los monarcas españoles estará en función de su personalidad y de sus inclinaciones particulares, pero, a la vez, también dependerá de la iniciativa de validos y ministros.

$* * *$

Por lo que sabemos positivamente, Felipe II no tenía una especial predilección por la música, aunque, por supuesto, la apreciaba. Sin embargo, su aportación es decisiva en el aspecto organizativo. Su minuciosidad en el control de todos los asuntos de su casa, bien conocida y estudiada, también alcanzó a la música. Desde que se estableció la corte en Madrid en 1561, Felipe II tuvo un empeño constante por reglamentar todo lo relativo a la organización de la casa real. En este sentido, la iniciativa de mayor alcance en lo que concierne a la totalidad de la casa real lo constituye su petición de un informe detallado acerca de la estructura de la Casa de Borgoña de su padre el Emperador, informe al que se añadirá una copia de la redacción de Olivier de la Marche sobre la casa del duque borgoñón Carlos el Temerario. El mencionado informe constituirá el núcleo de las Etiquetas por las que, modificadas y puestas al día, se regirá la vida palaciega en los reinados sucesivos. En ellas, se da cuenta de los oficios musicales, así como del cometido y retribución de los mismos. ${ }^{6} \mathrm{Al}$ margen de estas disposiciones generales, los únicos departamentos de la casa real para los que Felipe II ordenó redactar instrucciones específicas fueron la capilla y la caballeriza.

5. Para más detalle sobre el particular, vid: RoBledo 1978b; RoBLEDo1988a; RoBledo1988b.

6. HOFMANN 1985; RoBledo $1987 \mathrm{~b}$. 
Desde el punto de vista de la actividad musical, las constituciones y reglamentos para la capilla real ordenados por Felipe II que nos interesan son:

1. Leges et constitutiones capillae catholicae maiestatis a maioribus institutae, a Car[olo] Quinto studiose custoditae, hodierno die mandato regis catholici singulis sanctissime servandae. ${ }^{7}$ La redacción es de los primeros años del reinado de Felipe II, en todo caso anterior a 1568.

2. Estatutos que hasta agora se han guardado en la Capilla Imperial y se han de observar en la Real Capilla de Su Magestad conforme al uso de Borgoña. ${ }^{8}$

3. Advertencias de cómo se ha de ganar y repartir las distributiones que Su Magestad Católica ha mandado poner en la capilla de cantores de su capilla real y capellanes de altar desde primero de otubre de $1584 .{ }^{9}$ Aquí se dispone una forma mixta de retribución a los ministros de la capilla: una parte es a la usanza borgoñona y otra a la usanza castellana, lo que evidencia un especial maridaje entre la tradición franco-flamenca y la peninsular. Además, se especifica que el canto llano ha de ser el toledano, manteniendo, así, el privilegio concedido por la Santa Sede a los Reyes Católicos Isabel y Fernando de preservar en su capilla el canto llano de tradición hispánica.

Como complemento a las anteriores disposiciones, hay que decir que Felipe II creó el cargo de teniente de maestro de la capilla, que no existía antes, y que fundó hacia 1595 un colegio para los niños cantores como institución aneja a la capilla, para el cual se redactaron unas Constituciones especiales. ${ }^{10}$ Toda esta cuidadosa reglamentación sienta las bases del funcionamiento de la capilla real durante los reinados posteriores, al menos hasta el cambio de dinastía en 1701 .

Felipe II puso también un especial cuidado en el reclutamiento de músicos para la capilla real, especialmente en el caso de los flamencos, como lo demuestran las cartas personales dirigidas a Margarita de Parma, a Alejandro Farnesio y al duque de Alba, gobernadores respectivos de Flandes, solicitando maestros de capilla y organistas. ${ }^{11}$ De hecho, todos sus maestros de capilla y tenientes fueron flamencos. Se evidencia en ello el peso de la herencia borgoñona, el empeño por mantener el carácter de la institución que había paseado famosamente el emperador Carlos por Europa.

Hay un documento que muestra muy bien el interés de Felipe II hacia el buen funcionamiento sonoro de la capilla y, a la vez, la conciencia de sus limitaciones personales para emitir un juicio decisivo. Se trata de una nota escrita a su secretario Mateo Vázquez en 1584 sobre la prueba de cierto capellán para ingresar en la capilla real. Dice así:

7. E-Mpa, Administrativa, leg. 1.133. Vid. VAN DER STRAETEN 1867-1888, VII, 178-186.

8. $E-M n$, ms. $14.018 / 6$.

9. E-Mpa, Real Capilla, caja 76, leg. 5, no. 1. Otra copia en $E-M n$, ms. $14.018 / 3$. 14.017/9.

10. Hay diferentes copias en: E-Mpa, Administrativa, leg. 1.116; E-Mpa, Real Capilla, caja $105 ; E-M n$, ms.

11. Vid: VAN DE STRAETEN 1867-1888, VIII; BeCQUART 1967. 
«Yo vi hoy un poco de la misa dese capellán que dixo cantada, y no me pareció mal, aunque yo no lo entiendo, y pareciendo así a otros que lo entiendan mejor, se podrá tomar en la forma que dice el receptor...» ${ }^{12}$

Parece que, más allá de sus preferencias personales, lo que sobre todo cuenta para el rey prudente es consolidar la institución. Por otra parte, sin embargo, no es ajeno al placer que procura la música e, incluso, es capaz de emitir un juicio personal. Este aspecto aparece sobre todo en el ámbito privado de la correspondencia con sus hijas, ${ }^{13}$ pero también en el especialísimo trato de favor demostrado hacia el organista castellano Antonio de Cabezón que en sus últimos años llegó a gozar de un sueldo muy superior al de casi todos los criados de la casa real, desde luego superior al de los demás integrantes de la capilla real, y a quien parece que otorgó de facto calidad de maestro de capilla durante la estancia en la corte inglesa. ${ }^{14}$ De hecho, creo que el caso de Cabezón es único, no sólo en lo que respecta al patronazgo musical de Felipe II, sino al de los demás monarcas españoles de la dinastía Habsburgo. ¿No cabría hablar, pues, de un cierto equilibrio entre el gusto personal, el reconocimiento de la valía de ciertos individuos concretos, y las exigencias institucionales? Equilibrio hay, en otro orden de cosas, en los componentes de la capilla, repartidos entre flamencos y españoles, y en el repertorio utilizado en la misma, basado fundamentalmente en autores de la escuela franco-flamenca y de la escuela española, si bien es muy reseñable la presencia de la escuela romana (Palestrina) y de la veneciana (Andrea Gabrieli).

En lo que respecta al repertorio, no quiero dejar de mencionar, aunque sea un hecho muy conocido, la actitud de Felipe II hacia los villancicos en lengua vulgar que supuestamente prohibió por decreto en 1596. Y digo supuestamente, porque todas las menciones que tenemos al respecto proceden de fuentes secundarias: nadie conoce el decreto original. El texto, lacónico, de tal decreto lo suministra Vicente Pérez en $1791 .{ }^{15}$ La manera en que Pérez transcribe la disposición de Felipe II, ofreciendo día, mes y año, y su vinculación con la capilla real, donde pudo tener muy bien acceso a la fuente original, merecen que, en principio, le demos crédito. Pero la consulta de las restantes fuentes levanta cierta sospecha. Estas son, por orden cronológico: Cerone 1613, 197; ${ }^{16}$ Vera 1630, 196; Pedro París y Royo; ${ }^{17}$ Valls ca. 1742, fol. 207: ${ }^{18}$ Rodríguez de Hita 1757, fol. $2 r$. Pues bien, Cerone, refiriéndose imprecisamente a «los años del Señor de 1596», es escueto en su noticia. Vera sigue a Cerone, pero añade que los villancicos «ya se han buelto a introduzir...» París y Royo transcribe el pasaje de Cerone y añade, quizá tomando como punto de partida la adición de Vera: «Y esto fue observado hasta el Reynado del señor Rey Don Phelipe Quarto, en cuyo tiempo se bolvió a introducir la costumbre de cantar Villancicos en lengua vulgar, que aunque entonces se permitió con todas las cautelas necessarias, de que las letras fuessen

12. Riba García $1959,318$.

13. Vid.: Bouza Álvarez 1988.

14. Vid.: Robledo 1989b; Robledo 1989c.

15. E-Mn, M/762. Vid. Moll 1970, 82.

16. Vid. Moll 1970, 82.

17. Antes de 1731. Vid. Caballero Fernández-Rufete 1992, 333.

18. Vid. ANGLÈs-SubirÀ 1946, 196-197. 
vistas, y aprobadas por hombres Doctos, y de zelo Eclesiástico, y que la Música fuesse devota, y libre de los defectos que podían hazerla indecente para el Templo...» Valls reproduce casi literalmente el pasaje anterior de París y Royo, acreditándolo. Rodríguez de Hita sólo menciona de pasada la prohibición de Felipe II. Pero, y ahora volvemos al comienzo, Vicente Pérez añade al texto del decreto el comentario de París y Royo reproducido anteriormente, con alguna modificación y sin acreditarlo. En resumen, nos hallamos ante una sucesión de «glosas» sobre un hecho cuya autenticidad no está nada clara.

Me he detenido en lo anterior, porque todos hemos asumido la famosa prohibición de 1596 de manera acrítica. Pero, en definitiva, aún aceptando la existencia de la misma, lo que importa realmente es lo que Jaime Moll demostró de modo irrefutable: que tal prohibición nunca se llevó a cabo. ${ }^{19}$ Lo que importa es, pues, que la actitud de Felipe II se muestra flexible y receptiva hacia la práctica musical establecida que lo circunda; y no sólo eso, sino que en su capilla se potencia esa práctica con la magnificencia que cabe esperar de tan emblemática institución, interpretándose de manera sistemática obras policorales en latín y en lengua vulgar con el apoyo novedoso del basso seguente, práctica ésta última de la que la corte española es pionera. ${ }^{20}$

Contrasta el interés probado de Felipe II por el funcionamiento musical de la capilla con su aparente desinterés por la música de cámara, al menos desde el punto de vista institucional, porque es el caso que nunca tuvo músicos de cámara con plaza y salario fijos. No obstante, conviene hacer aquí una importante salvedad: en esta época la expresión «músico de cámara» se refiere fundamentalmente a un cantor que se acompaña con un instrumento. A lo largo de su reinado, fueron muchos los cantores de cámara que sirvieron al monarca, pero lo hicieron ocasionalmente, ya que procedían de la capilla real, de la Casa de la Reina, o bien no tenían asiento alguno en las casas reales. Sin embargo, hay que tener en cuenta que la plaza de Antonio de Cabezón y la de su hijo y sucesor, Hernando, eran de tañedores de tecla de capilla y cámara. En cualquier caso, para nosotros es muy significativo el grado de interés que despertó en el rey cierta intervención de Antonio de Villandrando - uno de esos músicos de cámara sin plaza - en la que cantó a su mesa un romance de contenido muy crítico hacia la política interior del momento. Lejos de pasar desapercibido a Felipe II, éste le hizo cantar repetidas veces dicho romance durante todo un verano. Y es que la música de cámara y el entorno donde se produce tienen unas connotaciones especiales sobre las que volveremos más adelante. ${ }^{21}$

El otro departamento de la casa real para el que Felipe II dispuso instrucciones específicas es la caballeriza, porque la imagen mayestática del rey, la apariencia «caballeresca» de él y de su corte dependen en buena medida del aparato con que maceros, reyes de armas, caballerizos y pajes acompañan la persona del monarca. Aquí, el emblema del poder que pregonan trompetas y atabales constituye una especie de tapiz sonoro que acompaña las idas y venidas del rey. Aquí

19. MOLL 1970.

20. ROBLEDO 1988b.

21. Para todo lo referente a los músicos de cámara de Felipe II, vid. RoBledo 1989a, 28-31. Para el suceso de Villandrando, vid. también: VillahERMOSA ca. 1615a, fols. 13r-15r; VIllaHERMOSA ca. 1615b, fols. 24r-26r; BouZA ÁlVAREZ 1994, 70-71; BouZa Álvarez 1997. 
también se educa a los pajes, futuros gentil hombres de la corte, que cuentan con una casa propia y con ordenanzas especiales para su gobierno — como los niños cantores de la capilla-. Los pajes han de conocer el manejo de las armas y la montura a caballo, para lo cual tienen maestro de esgrima y maestro de voltear, respectivamente. Pero también han de aprender a moverse con porte y elegancia, bien sea para servir la comida al monarca, bien para llevar hachas en la capilla, bien para su futura participación en ritos festivos tales como saraos y máscaras; de manera que cuentan además con un maestro de danzar que les instruye en agilidad corporal con sonora disciplina. $^{22}$

Otro aspecto de la intervención de Felipe II en los asuntos musicales de su casa es el relativo al entorno en el cual se educan sus hijos. Hay una parte dentro de este aspecto que no es especialmente significativa, por cuanto se refiere, una vez más, al marco institucional: cabe esperar que el monarca disponga lo necesario para que las infantas y los sucesivos príncipes herederos tengan siempre a su disposición un maestro de danzar, violones e, incluso, otros instrumentos, como sucede de hecho. Pero, aún así, la atención minuciosa con que Felipe II vigila todo cuanto puede afectar a sus hijos queda muy bien reflejada en la Instrucción que en 13 de junio de 1585 redacta el propio rey para el gobierno de la casa de Catalina Micaela cuando se convierte en duquesa de Saboya. En uno de sus apartados, dice lo siguiente:

«En los saraos o festines donde la infante se hallare se ha de guardar la orden y forma que por acá se acostumbra, no consintiendo otros bailes ni danças que sean indecentes y no dignas de aquel lugar...» 23

Interesa más la actitud de Felipe II hacia la extremada afición a la música del futuro Felipe III quien tenía como maestro de viola da gamba al veneciano Mateo Troilo. En 1596, con dieciocho años cumplidos, su preceptor García de Loaisa, que era también el máximo responsable de la capilla de Felipe II, redacta al rey un informe sobre el príncipe en el que se muestra muy severo sobre la mencionada afición a la música e insta al monarca para que la abandone, como se desprende del pasaje siguiente:

«Algunos exercicios tiene Su Alteça en la cámara que hasta aquí, por su edad y poca salud, eran lícitos. Agora ya podrían cesar [y] introducir otros, de suerte que nunca viviese ocioso, sino ocupado noblemente... El madrugar es cosa muy importante y, dándosel[e] orden que salga muy de mañana al campo, a caça o a hazer mal a un caballo o [a] armarse, le haría acostar temprano y dexar la música y templar la çena.» ${ }^{24}$

Pues bien, no sólo no abandonó el príncipe el cultivo de la música, sino que lo incrementó, parece que con el beneplácito de su padre, pues al año siguiente el propio Felipe II ordena per-

22. Pueden verse diferentes ordenanzas para la caballeriza, incluyendo las específicas para la casa de los pajes, en: E-Mrah, 9/683; $E-M p b, \mathrm{II} / 2096 ; E-M p b, \mathrm{II} / 578$.

23. $E-M p b, \mathrm{II} / 3127 . A-W n h$, Cod. 5624.

24. La cursiva es mía. $E-M p b$, II/1947, fols. $103 r-103 v$. Deseo agradecer a Andrea Sommer-Mathis la noticia de la existencia de otra fuente (incorrectamente fechada) con ligeras variantes: $A$-Wnh, Cod. 6739 , fols. $1 r-4 r$. 
sonalmente que se le encuadernen de nuevo «çinco libros de música y canto de Su Alteza que estaban muy viejos y maltratados». ${ }^{25}$ Podemos afirmar, por la documentación que hemos manejado, que este tipo de iniciativa personal del rey en lo concerniente a asuntos relativamente poco importantes de la casa del príncipe y de las infantas es totalmente inusual.

Creo que con todo lo anterior se puede intentar hacer un balance, siquiera sea provisional, de la significación que tiene la figura de Felipe II como sustentador de una actividad musical cortesana. Como hemos visto, sin excluir el interés personal por el disfrute de la música -el suyo propio o el de sus hijos-, su punto de vista fue principalmente institucional. Se halla lejos de ser el entusiasta y generoso mecenas de la música que han propuesto Higinio Anglés (1944) y Robert Stevenson (1961), como en esta misma sesión demuestra Michael Noone haciendo, por vez primera, un análisis historiográfico riguroso y objetivo. Pero, también es cierto que su actitud muestra una gran receptividad, una gran «prudencia». Volviendo al aspecto terminológico que mencionábamos al principio, creemos que, si bien no puede decirse que llevara a cabo un mecenazgo propiamente dicho, sí puede decirse que ejerció un sabio patronazgo.

\section{$* * *$}

Así como en el caso de Felipe II es la institución, la creación o consolidación de estructuras estables y bien reglamentadas, lo que determina fundamentalmente el sentido de sus iniciativas, en el caso de Felipe III resulta evidente que es la institución la que se acomoda a los gustos del monarca, hasta el punto de que no es posible entender el conjunto de reformas y ajustes que llevó a cabo en todo lo concerniente a la actividad musical en la corte sin tener presente su cultivo de la música, asiduo y entusiasta, y que se remonta, como hemos apuntado más arriba, al tiempo en que era príncipe heredero. En estos años, hay constancia de una serie de datos que demuestran lo anterior y que ofrezco de manera sintética. ${ }^{26}$

1591 - Se construyen para él dos guitarras.

- Se le compra un juego de violas da gamba.

- Se le encuadernan dos colecciones de «cançiones y motetes de Guerrero» para tañer con la viola da gamba.

- Se le copian cuatro libros de música. ${ }^{27}$

1596 - Es obsequiado con un claviórgano que se le envía desde Alemania. ${ }^{28}$

- Recibe libros de música de Flandes.

- Se le encuadernan trece libros de polifonía.

- Se copia un motete expresamente para su servicio.

25. E-Mpa, Administrativa, leg. 902.

26. Para más detalles sobre todo lo referente al cultivo de la música por parte de Felipe III, así como a diferentes manifestaciones musicales en la corte española durante su reinado, vid.: RoBlEDo 1987a; RoBLEDo 1989a, 27-41; RoBLEDO 1994.

27. E-Mpa, Administrativa, leg. 631.

28. CASARES 1986, 137. 
1597 - Posee un laúd, dos guitarras y dos juegos de violas da gamba.

- Posee un doble virginal.

- Se copia una misa de batalla expresamente para su servicio. ${ }^{29}$

Felipe III no abandonó la música al subir al trono. Consta documentalmente que continuó tañendo la viola da gamba, haciendo dúo a veces con Filippo Piccinini, tiorbista y violagambista boloñés al que reclutó como instrumentista de la capilla real y de la cámara y hacia el que demostró una deferencia poco común - incluyendo gratificaciones costosas- que ocasionó fuertes fricciones con otros músicos de la corte. ${ }^{30}$ Digamos, de pasada, que este trato de favor implicando agravios a terceros es difícilmente imaginable en el caso de Felipe II.

Tan sólo unos meses después de acceder al trono, Felipe III introduce en la capilla real instrumentos que nunca habían tenido cabida en ella: laúd, violas da gamba y clave — todos a cargo de otro italiano, Camilo Malfetano-, y, más tarde, instrumentos de la familia del violín, arpa y claviarpa, lira da gamba, la tiorba de Piccinini, y, ocasionalmente, guitarras, en virtud de todo lo cual cambia notablemente la fisonomía de la institución y de su repertorio. ${ }^{31}$ Es más que evidente que tal cambio en los efectivos de la capilla no es sino el reflejo de la práctica musical que el monarca llevaba años ejerciendo en su cámara.

Por otra parte, si bien vemos que la máxima institución devocional de la corte española se «italianiza» en lo concerniente al empleo de los instrumentos, a la vez podemos decir que se «españoliza», en primer lugar porque fueron muchos los cantores flamencos que decidieron regresar a su tierra tras la muerte de Felipe II, y en segundo lugar porque el máximo responsable de la capilla real en lo musical, el maestro de capilla, fue el flamenco españolizado Mateo Romero (= Mathieu Rosmarin), íntegramente educado en España y totalmente identificado con los géneros y estilos musicales cultivados en la Península. El propio Romero acompañaba a la guitarra los villancicos de Navidad y Reyes cantados por los niños cantores en la capilla. ${ }^{32}$ Además, desde 1606 el puesto de teniente será ocupado por dos de los compositores más representativos del primer barroco español, Gabriel Díaz Bessón y Juan Bautista Comes, cuyas obras fueron interpretadas en la institución madrileña.

Pero en lo que más destacaba Felipe III, al decir de todos los observadores y panegiristas de la época, era en la danza. La danza constituye un ejercicio esencial para la formación del futuro gobernante: danzar y tañer, dice el duque de Villahermosa dirigiéndose al futuro Felipe IV —es decir, en el entorno cortesano de Felipe III-, «hazen buena disposición, buena graçia y aire en la persona, y habitúan la composición del cuerpo para los afectos de ir grave, mesurado y apacible. El tiempo que en esto se ocupa no se ha de juzgar por perdido, antes por muy bien emplea-

29. E-Mpa, Administrativa, leg. 631.

30. ROBLEDO 1987a.

31. ROBLEDO 1987a.

32. ROBLEDO 1989a, 55 
do.» ${ }^{33}$ De manera que la exhibición ostentosa y con desenvoltura, ante cortesanos y embajadores, de quien encarnaba el poder había de ser cultivada y potenciada al máximo. De ello se encargó el valido del rey, el todopoderoso duque de Lerma quien, entre otras cosas, hizo venir de Milán un grupo de violones para constituir, por primera vez y para lo sucesivo, un conjunto estable en la Casa del Rey paralelo al que existía desde el reinado anterior en la Casa de la Reina, y cuyo cometido principal era suministrar música de danza. ${ }^{34}$

No debe sorprender el hecho de que estos violones, así como el maestro de danzar a cuya disposición se hallan, sean asentados en la caballeriza, ya que es inherente a este departamento de la casa real todo lo relativo a la apariencia externa del monarca, según apuntamos más arriba. Si el cultivo del alma es cometido de la capilla, el del cuerpo lo es de la caballeriza. Esta es la razón por la que Villahermosa, inmediatamente después de recomendar danzar y tañer al príncipe, lo insta a que se aplique «en el otro exercicio de ir a caballo en la silla, de la brida, que es lo substancial para las veras y la ordinaria para la graçia y compostura en los actos y paseos públicos y ordinarios, y en las entradas de las ciudades, que en esto se debe de poner todo cuidado para que se habitúe a ello...» ${ }^{35}$ Cabe imaginar que, si toda corte es, al cabo, reflejo de su monarca - de manera semejante a como la organización y disposición de cualquier domicilio privado refleja el estilo de vida y las inclinaciones de sus moradores-, la actividad musical en la corte de Felipe III nos brinda la imagen, metafórica e hiperbólica, de una realeza divertida, como se decía entonces, en ejercicios de relumbrante autocomplacencia.

Todavía tenía que tomar el joven rey otra iniciativa que alterase el funcionamiento musical de la corte anterior: institucionalizar la música de cámara a su servicio. Felipe III crea por primera vez un grupo estable de músicos de cámara en la Casa del Rey, con plaza y salario fijos, y lo hace un año antes de acceder al trono. Con ello, consolidaba el cultivo en la corte española de un género vocal profano de peculiares características, el tono, que se potenciará en el reinado de su sucesor. De nuevo, esta decisión que afecta a la estructura de la casa real viene determinada por una afición personal cultivada de manera asidua por el patrón. ${ }^{36}$

De entre los paisajes sonoros de la corte a los que ya nos hemos referido, el de la cámara tiene connotaciones muy especiales. La más obvia, aunque no por ello menos significativa, es la proximidad al monarca, el contacto directo con él y con sus más íntimos servidores. En la cámara cabe el diálogo o, al menos, cierta forma de complicidad entre sujetos que encarnan estamentos de tan diferente significación, como vimos al relatar la anécdota de Felipe II con Villandrando. En cierto modo, el músico de cámara comparte con el bufón ese territorio ambiguo en el que, a veces, parecen desdibujarse los límites de la jerarquía. Comparada con la actividad musical en la capilla real, es claro que la de la cámara cumple una muy distinta función. En aquélla,

33. Villahermosa ca. $1615 \mathrm{~b}$, fol. $6 r$. La redacción previa a la del pasaje anterior se halla en VillahermosA ca. $1615 \mathrm{a}$, fol. $8 r$

34. Para el empeño con que el duque de Lerma potenció la imagen del monarca a través de la fiesta y de la música, vid. STEIN 1993. Para el patronazgo musical del duque en su villa de Lerma, vid. DE VICENTE 1996.

35. Ca. 1615 b, ibid.

36. Para más detalles, vid. RoBledo 1989a. 
la música refuerza la sacralización del monarca, y lo hace porque se halla al servicio de la liturgia y del aparato ceremonial. En ésta, sirve para el esparcimiento, para que el monarca pueda elegir y escuchar el tipo de música que más le complace, cuantas veces lo desee, en un clima de distensión.

Pero, además, es posible entrever otra dimensión en la música de cámara, menos evidente que la anterior: una dimensión política, al propiciar, en ocasiones, el cultivo de la imagen del buen gobernante. Aunque rebase los límites cronológicos que enmarcan el presente trabajo, quiero referirme a un tratado sobre las disciplinas matemáticas que el jesuita escocés Hugh Sempel (latinizado Sempilius), catedrático en el Colegio Imperial de Madrid, escribió expresamente para su patrón, Felipe IV, más melómano éste que su padre Felipe III, y cuyos conocimientos musicales no se limitaban a tañer la viola da gamba, como su progenitor, sino que alcanzaban el ejercicio de la composición. Sempel comienza su tratado estableciendo un paralelismo entre el rey Salomón, a la vez sabio gobernante y músico, y el monarca español. Más adelante, tras haber recordado la utilidad de la música para la oratoria y la poesía, compara las diferentes disciplinas matemáticas con el conjunto de la monarquía; así, a la geometría le corresponden la agricultura y la arquitectura, a la aritmética la minería, a la óptica el comercio, a la estática el artesanado, a la cosmografía la vastedad de territorios que rige el cetro hispano, y a la música la «sagacidad y elocuencia de los habitantes» con que se engrandece la república. ${ }^{37}$ Es decir, trasladada a la figura del monarca, Felipe IV-Salomón, representaría la capacidad rectora e integradora del cuerpo social que a música y palabra en su dimensión retórica se les reconocía desde la Antigüedad.

Por otra parte, la cámara es lugar también para la Historia. En las etiquetas de Carlos el Temerario redactadas por Olivier de la Marche, que tan presentes estaban en la corte española, supuesta continuadora de la grandeza borgoñona, podemos leer:

«... y cuando el Duque ha trabajado todo el día en sus negocios y dado audiencia a cada uno, se retira en su cámara y los escuyeres van con él para hacerle compañía, y los unos cantan, los otros leen las historias romanas y cosas nuevas, los otros discurren de amores y de las armas...» ${ }^{38}$

Fernando Bouza ha señalado cómo la necesidad de la Historia para configurar la «apariencia» regia es claramente expuesta por el humanista García de Matamoros, y cómo bajo el velo de historias pasadas se puede recordar al monarca su responsabilidad en las tareas de gobierno, que es exactamente lo que aconteció con el romance de Villandrando citado más arriba. ${ }^{39}$ Transcendiendo su condición de crónica de los hechos pasados, la Historia actúa, pues, como legitimadora del poder y como ejemplo a seguir por el buen gobernante. Este, a través de historias puestas en música y en el ambiente recogido de su cámara puede ir labrando y corrigiendo su pro-

37. SEMPILIUS $1635,2-4,45,54,102$ y passim.

38. Vid. ROBLEDO $1987 \mathrm{~b}$.

39. BouZa Álvarez 1994, 43-44, 70-71. 
pia imagen. Por eso, en el ya citado Tratado practicable de la enseñanza de un buen príncipe, tratado todo él regido por el magisterio de la Historia, el duque de Villahermosa reserva un lugar destacado a la música de cámara - sin nombrarla como tal - para la formación del estadista, a la que dedica todo un capítulo: Del provecho que se saca de hazer cantar romançes y cosas sentenciosas a los príncipes moços, poniendo como ejemplo señero el famoso romance de Villandrando cantado al abuelo del joven príncipe:

«Algunas vezes, para instituír el ánimo del príncipe por vía de entretenimiento, se procura que los músicos que entran a tañer y cantar le canten romanzes y cosas sentenciosas para que se imprima en el ánimo, que tal vez el rey Phelippo, tan prudente y sabio cual él lo fue, a Villandrando, su músico, le mandó cantar tres y cuatro y muchas vezes algunos sentenciosos romances, y entre otros aquél que comiença "Sentado está el señor Rey", y con estos ramilletes y entretenimientos se imprimen en el ánimo del príncipe materias muy importantes a su estado, sin enfado de leyendas profundas y largas, quedándole con esto hecho el ánimo y el entendimiento al concepto de la buena razón, que aprovecha mucho en la ocasión tener en la memoria alguna coplilla de romance que se conserva y retiene con más facilidad que las sentencias dichas sin cadencia de verso. Otras vezes, es muy al propósito leerles algún historial discurso...» ${ }^{40}$

$$
* * *
$$

Para terminar, quisiera sólo apuntar tres aspectos que no pueden dejarse de lado en un estudio sobre el patronazgo musical cortesano y que habrán de ser abordados en mejor ocasión. El primero se refiere a la importancia de la Casa de la Reina como institución promocionadora de acontecimientos musicales y reclutadora de músicos. Baste decir que los primeros instrumentos e instrumentistas de la familia del violín de los que se tiene noticia en España vienen con Isabel de Valois, tercera esposa de Felipe II, constituyendo aquéllos más otro grupo de músicos de cámara sendos conjuntos estables casi medio siglo antes que los homónimos de la Casa del Rey. ${ }^{41}$

Los otros dos atañen específicamente a la historia social de la música. Uno de ellos tiene que ver con el diferente carácter que tiene el reclutamiento de servidores músicos en la corte dependiendo del departamento al que van destinados. Así, el reclutamiento de capellanes y cantores para la capilla se lleva a cabo de manera más o menos formal: es fundamentalmente su jefe, el capellán mayor, quien asume la responsabilidad de asentarlos, aunque, por supuesto, en muchas ocasiones se cuenta con la opinión del monarca. En la cámara, sin embargo, existe una mayor flexibilidad e informalidad. Durante el reinado de Felipe II, como dijimos, la manera en que desempeñaban su oficio los músicos de cámara era ocasional: algunas veces eran los músicos de la reina los que cantaban al rey, otras eran cantores de la capilla, otras no pertenecían a ninguno de los dos estamentos anteriores y servían sin salario fijo, con tan sólo una ración. Pero

40. Villahermosa ca. 1615 b, fols. $24 r$-26r. La redacción previa a la del pasaje anterior se halla en VILLAHERMOSA ca. $1615 a$, fols. $13 r-15 r$ (cit. en BouZA Álvarez 1997).

41. ROBLEDO 1987a. 
existe otro tipo de reclutamiento que, bajo una apariencia formal, constituye una especie de mundo aparte; éste es el de los tañedores de instrumentos, cuyo funcionamiento es esencialmente gremial, transmitiéndose los puestos en la corte de padres a hijos, o a hermanos, o a hijas a las que el rey otorga una plaza de tañedor como dote para que nombre ella a la persona que va a desempeñar el cargo, circunstancia ésta en la que, muy a menudo, una oportuna boda garantiza a los futuros descendientes de la pareja un puesto de instrumentista en la corte. La similitud entre el carácter corporativista de los tañedores de instrumentos y los gremios artesanales, entre los que se cuenta el gremio de violeros, ${ }^{42}$ por ejemplo, es obvia y crea una suerte de microestructuras económicas de tipo familiar-artesanal paralelas a la estructura económica general de la casa real, de la que aquéllas dependen, sin embargo, en última instancia.

El último aspecto implica un punto de vista diferente al que hemos venido adoptando. Hemos atendido a la labor de patronazgo en la corte desde la óptica autocomplaciente del poder: monarca, valido, institución, reglamentaciones, acontecimientos. Pero, ¿cuál es el punto de vista de los criados? ¿Cómo ven los sujetos que hacen posible esa dimensión sonora de la corte (tan grata a nuestros afanes y tan ensalzada por panegiristas) al patrón, a los jefes, a la estructura que los sustenta? Aquí hemos de abrir no la puerta grande jalonada de adornos y de jeroglíficos laudatorios, sino, expresándonos en términos domésticos, la puerta «de servicio», a través de la cual se vislumbra un panorama nada halagüeño, variable según las épocas, pero en conjunto teñido de amargura y de precariedad. Son muchos los testimonios fehacientes, sobre todo conforme avanza el siglo XVII, de las necesidades materiales que capellanes, cantores e instrumentistas de la casa real española sufren. Pero, como suele decirse... «esa es otra historia».

\section{Lista de abreviaturas}

A-Wnh. Viena. Österreichische Nationalbibliothek, manuscritos

E-Mca. Madrid. Archivo y Biblioteca de la Casa de Alba, Palacio de Liria

E-Mn. Madrid. Biblioteca Nacional

E-Mpa. Madrid. Archivo General del Palacio Real

E-Mpb. Madrid. Biblioteca del Palacio Real

E-Mrah. Madrid. Real Academia de la Historia

\section{Lista de fuentes y bibliografía citadas}

ANGLÈs, Higinio, 1944. La música en la corte de Carlos V, MME, II. Barcelona: CSIC (R/1984).

42. Vid. sobre el particular BORDAS 1994. 
Anglès, Higinio - SubIRÀ, José, 1946. Catálogo musical de la Biblioteca Nacional de Madrid. I. Manuscritos. Barcelona: CSIC.

ANNIBALDI, Claudio, ed., 1993. «Introduzione» a La musica e il mondo. Mecenatismo e committenza musicale in Italia tra Quattro e Settecento. Bolonia: Il Mulino.

ANNIBALDI, Claudio, 1997. «La musica e il mondo: il problema storiografico della committenza musicale fra teoria antropologica e prassi analitica». Conferencia inaugural del Congreso Internacional «Poder, mecenazgo e instituciones en la música mediterránea, 1400-1700, Avila, 18-20 de abril de 1997 (inédita).

Becquart, Paul, 1967. Musiciens néerlandais à la cour de Madrid. Philippe Rogier et son école (1560-1647). Bruselas: Palais des Académies.

Bordas, Cristina, 1994. «Harp builders in Madrid (1578-1700)». Proceedings of the International Historical Harp Symposium. Utrecht, 1992, ed. de M. van Schaik, Utrecht: STIMU.

Bouza Álvarez, Fernando, 1988. Cartas de Felipe II a sus hijas. Madrid: Turner.

Bouza Álvarez, Fernando, 1994. «La majestad de Felipe II. Construcción del mito real». $L a$ corte de Felipe II, ed. de José Martínez Millán, Madrid: Alianza.

Bouza Álvarez, Fernando, 1997. «El mecenazgo en la historia cultural y política». Comunicación presentada en el Congreso Internacional «Poder, mecenazgo e instituciones en la música mediterránea, 1400-1700» Avila, 18-20 de abril de 1997 (inédita).

Caballero Fernández-Rufete, Carmelo, 1992. «Dos memoriales sobre la música de los templos». Revista de Musicología, XV, 323-361.

CASARES, Emilio, ed., 1986. Francisco Asenjo Barbieri. Biografías y documentos sobre música y músicos españoles (Legado Barbieri). Vol. I. Madrid: Fundación Banco Exterior

CERONE, Pietro, 1613. El melopeo y maestro. Nápoles.

DE VICENTE, Alfonso, 1996. «Un mecenas musical en los comienzos del Barroco: Francisco Gómez de Sandoval y Rojas, duque de Lerma». El órgano de la colegiata de Lerma. Historia y restauración. Valladolid: Junta de Castilla y León, 9-34.

Hofmann, Christina, 1985. Das Spanische Hofzeremoniell von 1500-1700. Frankfurt am Main: Verlag Peter Lang.

MoLL, Jaime, 1970. «Los villancicos cantados en la capilla real a fines del siglo XVI y principios del siglo XVII». Anuario Musical, XXV, 81-96.

Palomino, Antonio, 1986. Vidas. Ed. de Nina Ayala Mallory. Madrid: Alianza.

PORTUS PEREZ, Javier, 1994. «El retrato vivo. Fiestas y ceremonias alrededor de un rey y su palacio». El Real Alcázar de Madrid. Dos siglos de arquitectura y coleccionismo en la corte de los reyes de España. Madrid: Comunidad de Madrid / Nerea, 112-130.

Riba García, Carlos, 1959. Correspondencia privada de Felipe II con su secretario Mateo Vázquez, 1567-1591. Madrid: CSIC.

Robledo, Luis, 1987a. «Vihuelas de arco y violones en la corte de Felipe III». Actas del Congreso Internacional «España en la música de Occidente» (Salamanca, 1985). Madrid: Ministerio de Cultura, vol. II, 63-76. 
RoBledo, Luis, 1987b. «La música en la corte madrileña de los Austrias. Antecedentes: las Casas Reales hasta 1556». Revista de Musicología, X, 753-796.

RoBledo, Luis, 1988a. «Sobre la capilla real de Felipe II». Nassarre, IV, 1-2, 245-248.

RoBledo, Luis, 1988b. «La capilla real en el reinado de Felipe II». III Semana de Música Española. El Renacimiento (Madrid. Festival de Otoño 1986). Madrid: Comunidad de Madrid, 249-262.

RoBledo, Luis, 1989a. Juan Blas de Castro (ca. 1561-1631). Vida y obra musical. Zaragoza: Institución «Fernando el Católico».

RoBledo, Luis, 1989b. «"Antonio”, un criado de lujo». Scherzo, 33, 68-70.

Robledo, Luis, 1989c. «Sobre la letanía de Antonio de Cabezón». Nassarre, V, 143-149.

ROBLEDO, Luis, 1994. «Questions of performance practice in Philip III's chapel». Early Music, XXII, 199-218.

RODRÍGUEZ DE HITA, Antonio, 1757. Diapasón instructivo. Madrid.

SEmPILIUS, Hugo, 1635. De mathematicis disciplinis libri duodecim ad Philippum IV Hispaniarum et Indiarum Regem Catholicum. Amberes.

StEIN, Louise, 1993. «Musical Patronage: The Spanish Royal Court». Revista de Musicología, XVI, 615-619.

Stevenson, Robert, 1961. Spanish Cathedral Music in the Golden Age. Berkeley: University of California Press (R/1976).

VALLS, Francisco, ms. ca. 1742. Mapa armónico práctico (E-Mn, M/1071).

VAn Der Straeten, Edmond, 1867-1888. La musique aux Pays-Bas avant le XIXe siècle. 8 vols. Bruselas.

VERA, fray Martín de, 1630. Instrucción de eclesiásticos. Madrid.

VillaHermosa, Francisco Gurrea de Aragón, duque de, ms. ca. 1615a. Tratado practicable de la enseñanza de un buen príncipe (en el lomo se lee: $E d u^{o n} / d[e] u[n]$ bu[en] / Prí[n]cip ${ }^{e} /$ por D/Fran ${ }^{c o} /$ de / Aragón $o^{n}(E-M c a$, Mss. 57) (se trata de la primera redacción del ms. que sigue).

VILlAHERmosa, Francisco Gurrea de Aragón, duque de, ms. ca. 1615b. EL / PRINCI / INSTUI (= El príncipe instituido [o instruido]) (E-Mpb, II/587) (se trata de una reelaboración del ms. anterior). 